ZOOLOGIA 28 (2): 186-192, April, 2011

doi: $10.1590 /$ S1984-46702011000200005

\title{
The influence of clutch and brood sizes on nesting success of the biscutate swift, Streptoprocne biscutata (Aves: Apodidae)
}

\author{
Mauro Pichorim
}

Departamento de Botânica, Ecologia e Zoologia, Universidade Federal do Rio Grande do Norte. Campus Universitário, Lagoa Nova, 59078-900 Natal, RN, Brazil. E-mail: mauropichorim@yahoo.com.br

\begin{abstract}
The nesting success of three colonies of Streptoprocne biscutata (Sclater, 1866), and the influence of clutch and brood size on nesting success of species were studied. Overall, apparent nesting success was 58\% and Mayfield nesting success was 53\%. Nest survival during incubation (64\%) was lower than during the nestling period (83\%). During incubation, clutches were lost to rain, desertion, predation, egg ejection, egg damage, and egg disappearance. During the nestling period, losses occurred due to offspring disappearance, nestling death by starvation, predation and falling. During both incubation and nestling periods, predation was low, while egg ejections and nestling starvation were the main causes of nest failure. Nest survival during incubation was directly proportional to clutch size, while during the nestling period it was inversely proportional to the brood size. Apparently, there seemed to be an advantage to having more eggs during incubation. However, if all eggs were to hatch during unfavorable weather the nest success could be low. These results suggest that when the breeding pairs face adversity during incubation, they control the brood size by ejecting part of the clutch.
\end{abstract}

KEY WORDS. Breeding success; egg ejection; clutch reduction; Mayfield method.

Swifts have high nesting success, possess behavioral and morphological adaptations for specific environments, and exhibit unique reproductive features among birds (CHANTLER \& Driessens 1995, Chantler 1999). They use inaccessible sites for resting and breeding, such as cliffs, caves and waterfalls, a strategy that protects their nests from potential predators. Some species show low success rates during incubation - e.g. Streptoprocne rutila (Vieillot, 1817), Aerodramus salangana (Streubel, 1848), Aerodramus maximus (Hume, 1878), Chaetura pelagica (Linnaeus, 1758), C. brachyura (Jardine, 1846) and Apus apus (Linnaeus, 1758) - (Lack \& Arn 1947, Weitnauer 1947, Fischer 1958, Medway 1962, Collins 1968, Pellantová 1975). However, nesting success changes with clutch size, as nests with larger clutches have higher success rates during incubation, and nests with fewer nestlings have higher success rates during the nestling period (see SNOw 1962, Collins 1968, Marín \& STILES 1992). Some authors suggest that mechanisms of clutch size control, like egg ejection, allow the parents to optimize the number of offspring (Koskimies 1950, O'CONNOR 1979, Pichorim $\&$ Monteiro-FilHo 2008). Maternal clutch reduction, as a clutch size adjustment mechanism, was already suggested for Ficedula hypoleuca (Pallas, 1764) (Aves: Muscicapidae) (LoвAто et al. 2006). This hypothesis has not been explored in swifts, although egg ejection is a widespread behavior in this family (MOREaU 1942, Lack \& Lack 1951, Medway 1962, Rowley \& OrR 1962, SNow 1962, Pellantová 1975, Whitacre 1989, Pichorim 2002, Pichorim \& Monteiro-Filho 2008). The objective of this study was to deter- mine the nesting success in S. biscutata, the influences of clutch and brood sizes on the breeding biology of this species, and further discuss the possibility of a mechanism of clutch size control.

\section{MATERIAL AND METHODS}

Three colonies of $S$. biscutata were studied in the eastern part of the state of Paraná, southern Brazil. The Anhangava colony, studied during 1993-1996 and 1999-2001, is a granitic cave located in the municipality of Quatro Barras $\left(25^{\circ} 22^{\prime} \mathrm{S}\right.$, $48^{\circ} 58^{\prime} \mathrm{W}, 1250 \mathrm{~m}$ ) which has an annual rainfall of approximately $2000 \mathrm{~mm}$ (a more detailed description of the locality can be found in Pichorim (2002)). The Serra do Capivari colony is a granitic crevice about $20 \mathrm{~m}$ high, $30 \mathrm{~m}$ deep and 0.3-1 m wide located in the municipality of Campina Grande do Sul $\left(25^{\circ} 11^{\prime} \mathrm{S}, 48^{\circ} 51^{\prime} \mathrm{W}, 1050 \mathrm{~m}\right)$. The inner walls of this crevice become wet during and immediately after rains, and the Atlantic Rainforest habitat surrounds this locality. The Arenitos colony, is located inside the Vila Velha State Park, municipality of Ponta Grossa $\left(25^{\circ} 15^{\prime} \mathrm{S}, 50^{\circ} 00^{\prime} \mathrm{W}\right.$, $1000 \mathrm{~m}$, Fig. 1). Natural grasslands, savanna and patches of Atlantic Forest with Araucaria angustifolia (Bertol.) Kuntze (Araucariaceae) dominate this locality. This site includes complex crevices and small caves, is rich in limestone, and has an area of five hectares. The crevices used as shelters and nest sites are 10-30 m high, 10-60 m long and $0.5-8 \mathrm{~m}$ wide. The walls are vertical, and water flows down 


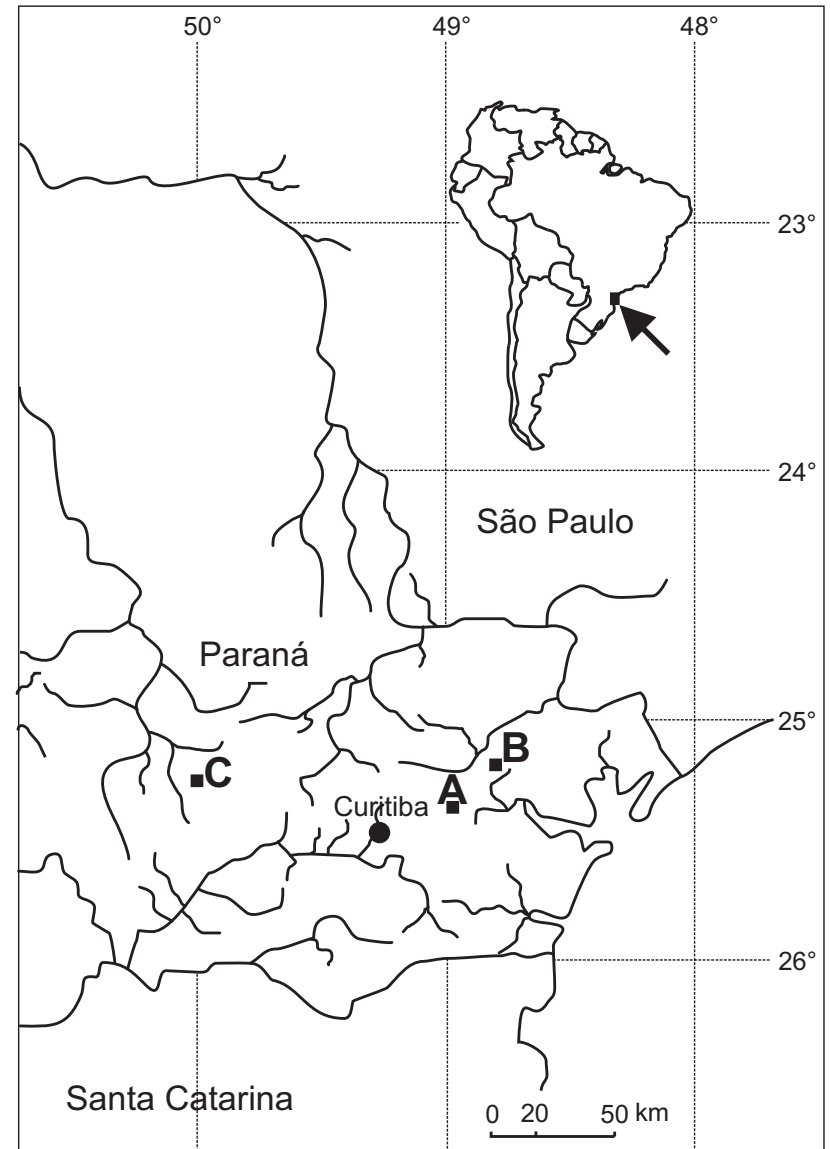

Figure 1. Biscutate Swift colonies studied in southern Brazil. (A) Anhangava, municipality of Quatro Barras, (B) Serra do Capivari, municipality of Campina Grande do Sul, and (C) Arenitos, Vila Velha State Park, municipality of Ponta Grossa.

over them only during or immediately after rains. The latter two colonies were studied from 1999 to 2001 . The population sizes estimated for these colonies was approximately 360 individuals at Anhangava, 190 individuals at the Serra do Capivari, and 1900 individuals at Arenitos (for more details see PICHORIM \& Monteiro-Filho 2010).

Nests were located and monitored, in the three colonies, from October (when nest construction begins) to mid-January (when the young fledge). During this period, each colony was examined every four days using flashlights, ladders and rock climbing equipment (carabineers, harnesses, ropes, and steel pitons) to locate and reach the nests. The date, location and reproductive stage of each nest was recorded. Each egg was marked with a pencil when first found, and the nestlings were banded with plastic rings, which were replaced with metallic ones when the birds were at least ten days old (metallic rings were supplied by the Centro Nacional de Pesquisa para
Conservação das Aves Silvestres/Instituto Chico Mendes de Conservação da Biodiversidade - CEMAVE/ICMBio).

The egg, nestling and nest success were calculated using percentages derived from proportions between successes and failures (apparent success), including a few nests which were not frequently observed, and by using Mayfield's method, which estimates the mortality rate as a ratio between failures and observation period (MAYFIELD 1961, 1975). An incubation period of 24 days and a nestling period of 33 days were considered in order to obtain the survival rates (following PICHORIM 2002), and to avoid rounding errors, the survival rates were calculated to four decimal points and percent survival to two decimal points (following MAYFIELD 1975). Nests were considered successful when at least one egg hatched and at least one nestling fledged. Nests, eggs or nestlings observed only once were not used in the Mayfield analyses. The differences between the Mayfield egg, nestling and nest success, of each reproduction stage were tested following Dow (1978), but the chi-square test was replaced with the G-test (alpha $=0.01)$ following ZAR (1999).

\section{RESULTS}

The apparent success of nests during the incubation period, the nestling period, and during the two periods combined was $66 \%$ (104 nests of 158), 88\% (92 nests of 104) and 58\% (92 nests of 158), respectively. During incubation, $59 \%$ of the monitored eggs hatched (188 of 318 eggs) and in the nestling period, $84 \%$ of the monitored young fledged (166 of 197 nestlings). From the time the eggs were laid, the apparent success of nestlings was 47\% (133 nestlings from 283 eggs were monitored during the entire period).

During the incubation period, 49 of the 153 studied nests were recorded as lost, during 2,617 nest-days of observation. The Mayfield nest survival rate during incubation was 0.9813 per day and 0.6357 for the entire incubation period (Tab. I). Nests with more eggs were more successful. Clutch sizes of one, two, three and four eggs were observed to have nest success rates of $0.3002,0.6774,0.8247$ and $1(G=18.3, \mathrm{df}=3, \mathrm{p}<0.01)$, respectively (Tab. I; Fig. 2). The causes of nest failure during incubation were egg disappearance (49\%), egg damage (18\%), egg ejection $(12 \%)$, nest predation (8\%), nest desertion (8\%) and nests falling due to rain (4\%) (Tab. II). Nests were lost to rain when crevices were flooded by intense rains at the Arenitos colony. When nests were lost by desertion, the eggs remained in the nest throughout the incubation period. In at least one nest, the nesting pair did not abandon the eggs before the expected hatching date. Loss by predation was only considered when the carcasses or partial remains of parents were found near the eggshells, within the nests. Nests failed due to egg ejection, when the eggs were outside the nests, either intact or with small cracks. Nests lost by egg damage only had broken eggshells in the nest cup, assuming the loss was due to acci- 


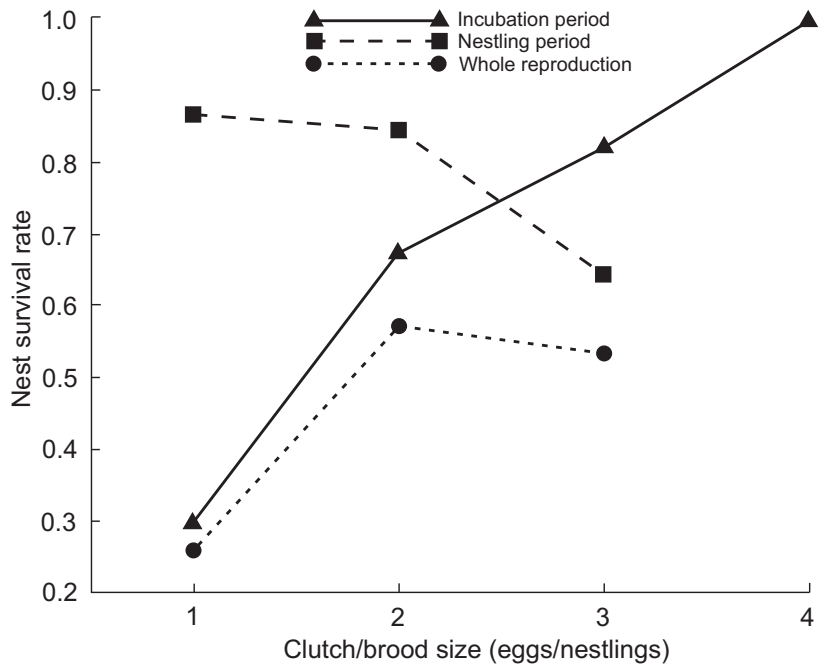

Figure 2. Mayfield survival rates of Streptoprocne biscutata nests with different clutch and brood sizes during each reproductive stage, observed in three colonies from southern Brazil. Nests with a brood size of one showed a higher survival rate than nests with a clutch size of one $(\mathrm{G}=14.5, \mathrm{df}=1, \mathrm{p}<0.01)$. The same pattern is evident when comparing nests with brood size and clutch size of two $(\mathrm{G}=6.9$, $\mathrm{df}=1, \mathrm{p}<0.01)$, but there was no difference in the survival rates of nests with three eggs and nestlings ( $G=1.1$, $\mathrm{df}=1, \mathrm{p}>0.01$ ).

dental damage or to unidentified predation. Egg disappearance was a term used to define the circumstance in which eggs were not found in a nest, yet there was no evidence indicating the cause of disappearance. In these cases, there was no evidence of predation or ejection. In all the observed nests, the pairs bred only once during the breeding season. If a complete clutch was lost, no supplementary clutch was laid in the same nest. On several occasions during incubation, broken eggs were observed on the ground of the study areas. However, the nests from which these eggs originated could not be identified. During the 1994 to 1996 breeding seasons, 13, 10 and 11 broken eggs, respectively, were found in the Anhangava colony. In November 2001, five broken eggs were found on the ground on the $1^{\text {st }}$ day, nine on the $8^{\text {th }}$ day, five on the $19^{\text {th }}$ day and two on the $26^{\text {th }}$ day, at the Arenitos colony. These last two eggs had well-developed embryos.

During incubation, a few individual eggs were lost without the loss of the entire nest. From a total of 225 eggs in 104 successful nests, 188 hatched and 37 were lost. The daily probability that eggs survive individual loss was 0.9901, and their survival rate over the whole incubation period was 0.5007 (Tab. I). Loss of individual eggs was due to disappearance (which could be attributed to undetected predation or ejection/falling), ejection, failure to hatch (the egg remained in the nest during the incubation period) and damage (Tab. II). Egg disappearance was the main cause of the loss of individual eggs during incubation (41\%). The ejection of part of the clutch was the second greatest cause of loss of individual eggs without the loss of the entire nest (35\%). Most likely due to intentional ejections (not accidental), because eggs were frequently found beside the nests without any damage, and in five instances, the eggs were ejected again when put back in the nest. Failure to hatch accounted for $22 \%$ of individual egg loss. In these cases, at least one egg of the same clutch hatched, and the other remained in the nest for about one week until it was ejected. Only one egg was lost by physical damage without loss of the entire nest (3\%). This egg was cracked inside the nest with some exposed yolk and albumen near another intact egg.

During the nestling period, it was possible to use survival information from 104 nests. Of this sample, 13 nests were re-

Table I. Mayfield survival rates of S. biscutata from southern Brazil a.

\begin{tabular}{|c|c|c|c|c|c|}
\hline Item & Clutch/Brood sizes $(\mathrm{N})$ & Exposure days & Number of losses & Daily survival & Total survival \\
\hline \multirow{5}{*}{ Nests } & One $(23 / 19)$ & $327 / 450$ & $16 / 2$ & $0.9511 / 0.9956$ & $0.3002 / 0.8646(0.2596)^{b}$ \\
\hline & Two $(107 / 76)$ & $1862 / 1758$ & $30 / 9$ & $0.9839 / 0.9949$ & $0.6774 / 0.8447(0.5722)^{b}$ \\
\hline & Three (19/9) & $377 / 151$ & $3 / 2$ & $0.9920 / 0.9868$ & $0.8247 / 0.6450(0.5319)^{b}$ \\
\hline & Four $\left(4 /-{ }^{c}\right)$ & $51 /-$ & $0 /-$ & $1 /-$ & $1 /-$ \\
\hline & All $(153 / 104)$ & $2617 / 2359$ & $49 / 13$ & $0.9813 / 0.9945$ & $0.6357 / 0.8336(0.5299)^{b}$ \\
\hline \multirow{5}{*}{$\begin{array}{l}\text { Eggs and } \\
\text { Nestlings }\end{array}$} & One $(7 / 17)$ & $129 / 419$ & $0 / 0$ & $1(1) d / 1(1)^{d}$ & $0.3002 / 0.8646(0.2596)^{b}$ \\
\hline & Two $(154 / 134)$ & $2638 / 3316$ & $13 / 4$ & $0.9951(0.8888)^{d} / 0.9988(0.9612)^{d}$ & $0.6021 / 0.8119(0.4888)^{b}$ \\
\hline & Three $(48 / 21)$ & $781 / 360$ & $16 / 4$ & $0.9795(0.6083) d / 0.9889(0.6919)^{d}$ & $0.5017 / 0.4463(0.2239)^{b}$ \\
\hline & Four $\left(16 /-{ }^{c}\right)$ & $198 /-$ & $8 /-$ & $0.9596(0.3717) \mathrm{d} /-$ & $0.3717 /-$ \\
\hline & All $(225 / 172)$ & $3746 / 4095$ & $37 / 8$ & $0.9901(0.7876)^{d} / 0.9980(0.9361)^{d}$ & $0.5007 / 0.7803(0.3907)^{b}$ \\
\hline
\end{tabular}

a For details of calculations see MAYFIELD $(1961,1975)$. The sequence of data presentation is "incubation period"/"nestling period". A 24-day incubation period and a 33-day nestling period is assumed (following PICHORIM 2002). ${ }^{\mathrm{b}}$ Combined survival (incubation and nestling periods together). ${ }^{\mathrm{c}}$ Broods of four nestlings were not found. ${ }^{\mathrm{d}}$ Survival rate during the period without the loss of the entire nest. 
corded as lost in 2,359 nest-days, resulting in a daily nest survival rate of 0.9945 and the nest survival rate for the period of 0.8336 , which was higher than nest survival during the incubation period ( 0.6357$)(\mathrm{G}=12.5, \mathrm{df}=1, \mathrm{p}<0.01)$. It was observed nests with 1-3 nestlings and those with one nestling had a higher survival rate $(0.8646)$ than others $(0.8447$ for two nestlings and 0.6450 for three nestlings) (Tab. I; Fig. 2). Nests with a brood size of one showed a higher survival rate than nests with a clutch size of one $(\mathrm{G}=14.5$, df $=1, \mathrm{p}<0.01)$. The same pattern is evident when comparing nests with brood size and clutch size of two $(\mathrm{G}=6.9$, $\mathrm{df}=1, \mathrm{p}<0.01)$, but there was no difference in the survival rates of nests with three eggs and nestlings $(G=1.1$, $\mathrm{df}=1, \mathrm{p}>0.01)$, although the success during the incubation period was higher in absolute terms. The causes of nest loss during the nestling period were as follows: disappearance (46\%), death by starvation (23\%), predation (15\%) and death by falling (15\%) (Tab. II). Nestling disappearance may be attributable to unidentified predation or falling. Nests lost by nestling starvation had dead nestlings with no fat and little content in their gizzards. In two of the observed nests, the nestlings were alive on a previous visit, but were weak, cold and showed lethargic movements. Loss by predation was only considered when the carcasses or partial remains of the nestlings were found in or near the nests. In nests lost by nestlings falling, the nestlings on the ground appear to be immediately below the nest.

During the nestling period, some individual nestlings were missing without the loss of the entire nest. A total of 172 nestlings in 91 successful nests were considered, of which 164 fledged and eight failed. The daily probability that nestlings survive individual loss was 0.9980 and their survival rate over the whole nestling period was 0.7803 (Tab. I). Nestling survival was higher than egg survival $(\mathrm{G}=41.3, \mathrm{df}=1, \mathrm{p}<0.01)$. Nestlings from nests with one chick had a higher survival rate than those from nests with two or three chicks (respectively: 0.8646, 0.8119, 0.4463, $\mathrm{G}=12.6$, $\mathrm{df}=2, \mathrm{p}<0.01$ ) (Fig. 3). Losses of individual nestlings occurred by starvation (50\%),

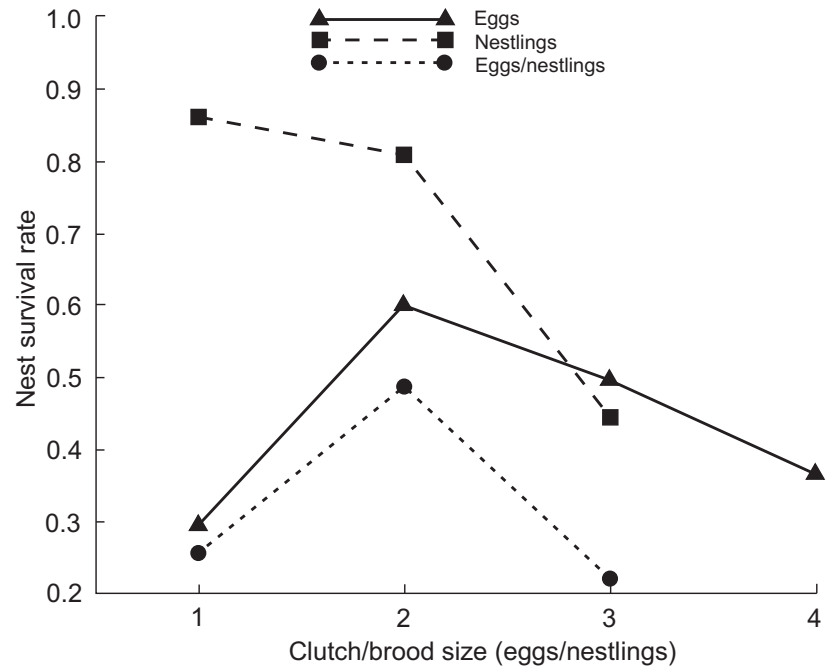

Figure 3. Mayfield survival rates of eggs, nestlings and eggs-nestlings of Streptoprocne biscutata in nests of different clutch and brood sizes, observed in three colonies from southern Brazil.

disappearance (25\%), and falling (25\%) (Tab. II). Four nestlings died by starvation without loss of the entire nest. Among these, two nests were found with a dead nestling and a live sibling which later fledged. On two other occasions, dead nestlings were found out of the nests, nearby or next to the nest. Two nestlings disappeared without the loss of the entire nest. They were taken by predators or had fallen, but there was no evidence of carcasses or partial remains. Two individual losses through falling were observed, and confirmed by the discovery of dead nestlings below the nests.

The likelihood that eggs, at the beginning of the incubation period, could produce fledglings was 0.3907 (the product of egg survival during the incubation period and nestling survival during the nestling period). This probability was highest

Table II. Causes of nest and egg/nestling failures during the incubation and nestling periods observed in three S. biscutata colonies from southern Brazil.

\begin{tabular}{|c|c|c|}
\hline Causes of failure & Entire clutch/brood lost $(\mathrm{N})$ & Egg/nestling lost without loss of the entire nest $(\mathrm{N})$ \\
\hline Disappearance ${ }^{a}$ & $24 / 6$ & $15 / 2$ \\
\hline Damages/Starvation ${ }^{\mathrm{b}}$ & $9 / 6$ & $1 / 4$ \\
\hline Ejection ${ }^{c}$ & 6 & 13 \\
\hline Failure to hatch ${ }^{d}$ & 4 & 8 \\
\hline Predation ${ }^{\mathrm{e}}$ & $4 / 2$ & $0 / 0$ \\
\hline Falling & $2^{f} / 2^{g}$ & $0 / 2^{g}$ \\
\hline
\end{tabular}


for nests with clutch and brood sizes of two (0.4888) and lowest for nests with clutch and brood sizes of three (0.2239) (Tab. I; Fig. 3). The nest survival rate during the entire reproductive period was 0.5299 (the product of the nest survival rate during the incubation period and the nest survival rate during the nestling period). Nests with clutch and brood sizes of two had the highest survival rate $(0.5722)$ and nests with clutch and brood sizes of one had the smallest survival rate (0.2596) (Tab. I; Fig. 2).

Predation was low during the incubation and nestling periods. The following potential predators were recorded near the nest sites: small rodents [Akodon Meyen, 1833 (Muridae), and Rattus Fischer, 1803 (Muridae), Didelphis albiventris Lund, 1840 (Didelphidae), Philander opossum (Linnaeus, 1758) (Didelphidae), Nasua nasua (Linnaeus, 1766) (Procyonidae), and birds like Tyto alba (Scopoli, 1769) (Tytonidae) and Cyanocorax chrysops (Vieillot, 1818) (Corvidae)]. Two P. opossum near recently predated nests were captured (observations cited in PICHORIM 2002). In 2000 and 2001, one T. alba was observed using the same crevice that housed the Capivari colony as a roosting site. In many instances, flocks of four to ten C. chrysops and coatis were observed near the crevices and ledges with nests, at the Arenitos colony. However, these species, or the others cited above, were never observed preying on S. biscutata nests.

\section{DISCUSSION}

Nests with more eggs had better performance during incubation, showing the highest survival rate for the entire reproductive period in clutches $>2$ eggs. In Aerodramus spodiopygius (Peale, 1848) (Apodidae), egg success was also high in larger clutches (TARBURTON 1987). Apparently, larger clutches increased nest survival during incubation. However, during the nestling period, the highest success occurred in nests with fewer nestlings. In A. apus, larger broods also had lower success (PERRINS 1964, LACK \& LACK 1951), and in Apus pallidus (Shelley, 1870) (Apodidae), smaller broods were more productive during bad weather (Cucco \& Malacarne 1996a). In S. biscutata, nest survival during incubation was directly proportional to clutch size, and during the nestling period, it was inversely proportional to the brood size. Apparently, there is an advantage to having more eggs during incubation. However, if all eggs hatch in unfavorable conditions the nest success can be low. Therefore, it is possible that there is some control of brood size in this species, like the observed egg ejection behavior. It is possible that the eggs missing during incubation were probably also ejections, given the lack of predation evidence. Furthermore, during the incubation period, several broken eggs were observed on the ground, with their internal contents, in caves and rifts beneath the nest sites, suggesting that predators did not take the eggs that disappeared. For other swifts, broken eggs near the nests and the ejection of part of the clutch have been interpreted as eggs that fell accidentally or during disputes over the nest site (see Moreau 1942, Koskimies 1950, Lack \& Lack 1951, Medway 1962, Rowley \& Orr 1962, Snow 1962, Pellantová 1975, O'Connor 1979). It is interesting to emphasize that ejected $A$. apus eggs hatch when they are placed in an incubator, ruling out the possibility of ejection due to infertility or embryo death (O'ConNor 1979). As during incubation, few cases with clear signs of predation were found during the nestling period. It is probable that the disappearance of nestlings was mainly due to undetected falls. In the cases of death by starvation, some nestlings died out of the nests, or were observed next to the nest as being cold and showing lethargic movements. Thus, nutritional deficiencies are responsible directly (death by starvation) or indirectly (falls due movements) for the great majority of failures during the nestling period. In the Apodidae, deaths of nestlings by falling or due to undernourishment are the most commonly reported causes of failure (see MOREAU 1942, Knorr 1961, Hunter \& Baldwin 1962, Pellantová 1975, Langham 1980, Whitacre 1989, Рichorim 2002). Therefore, it is probable that $S$. biscutata lays an optimal clutch size to increase the nest success during incubation. However, if the pair faces climatic difficulties, the birds tend to eject part of the clutch, reducing the number of nestlings to be reared. Climatic changes provoke a reduction in food availability, generating physical stress, which can provoke the ejection of part of the clutch. This mechanism regulates the number of nestlings to be fed according to the physical condition of the nesting pair. Following this hypothesis, for the birds food availability is sufficient during good weather to maintain good physical condition, and consequently, they can feed larger broods. Nestling growth of S. biscutata in manipulated nests is inversely proportional to brood size, suggesting that egg ejection is a mechanism for controlling brood size in that species (Pichorim \& MonTeIroFilHo 2008). It should be noted that the nests with clutch and brood sizes of two achieved the highest survival rates. The brood and clutch size of two had the best performance and most likely this number works as a selective pressure in this species, because the number of eggs and nestlings are the most frequent.

In S. biscutata there are doubts whether clutches $>2$ eggs are laid by only one female (РісноRIM 2002). If collective clutches occur, they also guarantee higher nest success during incubation (nests with four eggs had 100\% survival). However, nest helpers apparently do not occur in S. biscutata, and only one pair feeds the nestlings (Рichorim 2002). Therefore, to rear a surplus of nestlings in adverse conditions is wasteful, and it is possible that egg ejection acts as a control mechanism. This hypothesis could be rejected if it is assumed that incubating a larger clutch does not require additional energetic investment and it could promote nestling selection by sibling competition. However, nestlings of natural broods of three can survive several days of undernourishment before death. Large broods of $A$. apus can survive for a long time in bad weather, increasing the length of the nestling period and the energy investment of the nesting pair. In smaller broods, nest success was inde- 
pendent of climatic conditions (LACK \& LACK 1951). In general, swift nestlings have great resistance to food deficits (see O'Connor 1979, Tarburton 1987, Chantler \& Driessens 1995, Cucco \& Malacarne 1996a). Langham (1980) observed deaths by starvation, only during the two last weeks of development, in two nestling broods of Aerodramus fuciphagus (Thunberg, 1812) (Apodidae). Artificially enlarged broods of $A$. spodiopygius raise the number of feeding visits by the parents, suggesting that larger broods do not naturally occur in this species due to reduction of life expectancy of the adult birds (TARBURTON 1987). Although larger broods of $A$. apus are visited more frequently by parents (Pellantová 1981, Martins \& Wright 1993a), the nestlings are lighter at the end of nesting period (MarTins \& WRIGHT 1993b). Cucco \& Malacarne (1996a, b) state that the size of the brood increases the frequency of feeding visits in nests of $A$. pallidus, sacrificing the reserves of the parents. LeE \& KANG (1994) showed that the ability of the adults to raise the nestlings and the insurance against reproductive failure was provided by laying more than the usual number of eggs in the clutch, which can influence the clutch sizes in A. maximus and A. fuciphagus. Nestlings of $A$. apus apparently die exclusively from starvation (LACK 1956, O'CONNor 1979, Martins \& Wright 1993a). In some species, pairs with large clutch sizes show a dangerous decrease in body mass (Martins \& Wright 1993b, Chantler 1999). In $A$. apus, manipulated broods $>3$ (the natural limit) always loose at least one chick, suggesting that just one extra nestling increases the brood above the maximum limit (MarTins \& WRIGHT 1993a). Under bad climatic conditions, A. apus broods of three lost two nestlings, and the survivor was lighter on average than nestlings of a brood of three in a good climate (LACK \& LACK 1951). In bad environmental conditions, the great resistance to starvation of Apodidae nestlings probably affects the nesting success and survival of the breeding pair. Furthermore, energy deficits incurred by adults during one breeding effort can influence future nesting success. It is probable that to avoid raising extra nestlings, only the pairs in good physical condition allow the hatching of more than two eggs. The hypothesis that adverse conditions can elicit parental family size adjustment at every stage of reproduction without the need to depend on sibling competition was already suggested for Ficedula hypoleuca (LoвAто et al. 2006). As discussed above, indirect support can be found for clutch reduction as a clutch size adjustment mechanism in S. biscutata, showing that this behavior is not too restricted. Thus, more detailed investigation in this area is needed, including additional experimental analyses.

\section{ACKNOWLEDGMENTS}

The Conselho Nacional de Desenvolvimento Científico e Tecnológico (CNPq) provided the financial support, and the Programa de Pós-Graduação em Zoologia of the Universidade Federal do Paraná provided institutional support. The Instituto
Ambiental do Paraná (IAP) allowed access to Vila Velha State Park. James J. Roper assisted with the statistical analyses. Alexandre Lorenzetto, Arthur A. Bispo de Oliveira, Aline Dal'Maso Ferreira, Juliano Ribeiro, and Maximiliano Niedfeld helped during the field activities. I appreciate the improvements in English usage made by James Armacost, through the Association of Field Ornithologists' program of editorial assistance.

\section{LITERATURE CITED}

Chantler, P. 1999. Family Apodidae (swifts), p. 388-457. In: J. del Hoyo; A. Elliott \& J. Sargatal (Eds). Handbook of the birds of the world. Barcelona, Lynx Edicions, vol. 5, 759p. Chantler, P. \& G. Driessens. 1995. Swifts, a guide to the swifts and treeswifts of the world. East Sussex, Pica Press, 237p.

Collins, C.T. 1968. The comparative biology of two species of swifts in Trinidad, West Indies. Bulletin of the Florida State Museum 11: 257-320.

Cucco, M. \& G. Malacarne. 1996a. Effect of food availability on nestling growth and fledging success in manipulated Pallid Swift broods. Journal of Zoology 240: 141-151.

Cucco, M. \& G. Malacarne. 1996b. Reproduction of the Pallid Swift (Apus pallidus) in relation to weather and aerial insect abundance. Italian Journal of Zoology 63: 247-253.

Dow, D.D. 1978. A test of significance for Mayfield's method of calculating nest success. Wilson Bulletin 90: 291-295.

Fischer, R.B. 1958. The breeding biology of the Chimney Swift Chaetura pelagica (Linnaeus). New York State Museum and Science Service Bulletin 368: 1-141.

Hunter, W.F. \& P.H. BALDwin. 1962. Nesting of the Black Swift in Montana. Wilson Bulletin 74: 409-416.

KNORR, O.A. 1961. The geographical and ecological distribution of the Black Swift in Colorado. Wilson Bulletin 73: 155170 .

Koskimies, J. 1950. The life of the swift, Micropus apus (L.), in relation to the weather. Annales Academiae Scientiarum Fennicae 15: 1-151.

LACK, D. 1956. A review of the genera and nesting habits of swifts. Auk 73: 1-32.

LACK, D. \& H. ARn. 1947. Die Bedeutung der Gelegerösse beim Alpensegler. Ornithologische Beobachter 44: 188-210.

LACK, D. \& E. LACK. 1951. The breeding biology of the swift Apus apus. Ibis 93: 501-546.

LANGHAM, N. 1980. Breeding biology of the Edible-nest Swiftlet Aerodramus fuciphagus. Ibis 122: 447-461.

LeE, P.G. \& N. Kang. 1994. The reproductive strategies of ediblenest swiftlets (Aerodramus spp.). Bulletin of the British Ornithologists' Club 114: 106-113.

Lobato, E.; J. Moreno; S. Merino; J.J. Sanz; E. Arriero; J. Morales; G. Tomás \& J. MartíneZ-DE-la-Puente. 2006. Maternal clutch reduction in the Pied Flycatcher Ficedula hypoleuca: an undescribed clutch size adjustment mechanism. Journal of Avian Biology 37: 637-641. 
Marín, A.M. \& F.G. Stiles. 1992. On the biology of five species of swifts (Apodidae, Cypseloidinae) in Costa Rica. Western Foundation of Vertebrate Zoology 4: 287-351.

Martins, T.L.F. \& J. Wright. 1993a. Brood reduction in response to manipulate brood sizes in the Common Swift (Apus apus). Behavioral Ecology and Sociobiology 32: 61-70.

Martins, T.L.F. \& J. Wright, 1993b. Cost of reproduction and allocation of food between parent and young in the swift (Apus apus). Behavioral Ecology 4: 213-223.

Mayfield, H. 1961. Nesting success calculated from exposure. Wilson Bulletin 73: 255-261.

MAYFIELD, H. 1975. Suggestions for calculating nest success. Wilson Bulletin 87: 456-466.

Medway, L. 1962. The swiftlets (Collocalia) of Niah Cave, Sarawak - Part I. breeding biology. Ibis 104: 45-66.

Moreau, R.E. 1942. The breeding biology of Micropus caffer streubelli Hartlaub, the White-rumped Swift. Ibis 84: 27-49.

O'CONNOR, R.J. 1979. Egg weights and brood reduction in the European Swift (Apus apus). Condor 81: 133-145.

Pellantová, J. 1975. The course of breeding of the Swift (Apus apus Linn.). Zoologické Listy 24: 249-262.

Pellantová, J. 1981. The growth of young of the swift, Apus apus, in relation to the number of nestlings, temperature, feeding frequency and quantity of food. Folia Zoologica 30: 59-73.

Submitted: 09.II.2010; Accepted: 08.X.2010.

Editorial responsibility: Kleber del Claro
PerRINS, C.M. 1964. Survival of young swifts in relation to brood size. Nature 201: 1147-1148.

Pichorim, M. 2002. The breeding biology of the Biscutate Swift, Streptoprocne biscutata (Apodidae) in southern Brazil. Ornitologia Neotropical 13: 61-84.

Pichorim, M. \& E.L.M. Monteiro-Filho. 2008. Brood size and its importance for nestling growth in the Biscutate Swift (Streptoprocne biscutata, Aves: Apodidae). Brazilian Journal of Biology 68: 851-857.

Pichorim, M. \& E.L.M. Monteiro-Filho. 2010. Population size, survival, longevity, and movements of the Biscutate Swift in southern Brazil. Annales Zoologici Fennici 47: 123-132.

Rowley, J.S. \& R.T. Orr. 1962. The nesting of the White-naped Swift. Condor 64: 361-367.

SNOw, D.W. 1962. Notes on the biology of some Trinidad swifts. Zoologica 47: 129-139.

TARBURTON, M.K. 1987. An experimental manipulation of clutch and brood size of White-rumped Swiftlets Aerodramus spodiopygius of Fiji. Ibis 129: 107-114.

Weitnauer, E. 1947. Am Neste des Mauerseglers, Apus apus apus (L.). Ornithologische Beobachter 44: 133-182.

WhitACRE, D.F. 1989. Conditional use of nest structures by Whitenaped and White-collared Swifts. Condor 91: 813-825.

ZAR, J.H. 1999. Biostatistical analysis. New Jersey, PrenticeHall International Editions, $4^{\text {th }}$ ed., XII+663p. 